TI 2015-025/VIII

Tinbergen Institute Discussion Paper

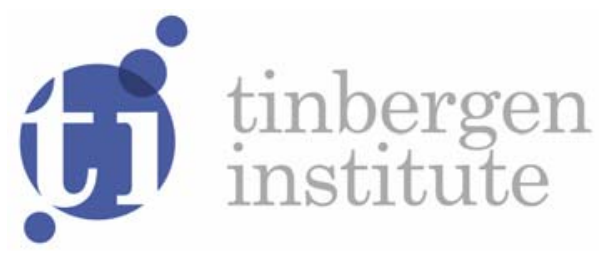

\title{
Miles, Speed and Technology: Traffic Safety under Oligopolistic Insurance
}

Maria Dementyeva

Erik T. Verhoef

Faculty of Economics and Business Administration, VU University Amsterdam, and Tinbergen Institute, the Netherlands. 
Tinbergen Institute is the graduate school and research institute in economics of Erasmus University Rotterdam, the University of Amsterdam and VU University Amsterdam.

More TI discussion papers can be downloaded at http://www.tinbergen.nl

Tinbergen Institute has two locations:

Tinbergen Institute Amsterdam

Gustav Mahlerplein 117

1082 MS Amsterdam

The Netherlands

Tel.: +31(0)20525 1600

Tinbergen Institute Rotterdam

Burg. Oudlaan 50

3062 PA Rotterdam

The Netherlands

Tel.: +31(0)10 4088900

Fax: +31(0)10 4089031 


\title{
Miles, speed, and technology: Traffic safety under oligopolistic insurance
}

\author{
Maria Dementyeva*, Erik T. Verhoef* \\ Department of Spatial Economics, Vrije Universiteit Amsterdam, De Boelelaan 1105, \\ 1081 HV Amsterdam, The Netherlands,
}

and Tinbergen Institute, Gustav Mahlerplein 117, 1082 MS Amsterdam, The Netherlands

\begin{abstract}
We study road safety when insurance companies have market power, and can influence drivers' behavior via insurance premiums. We obtain first- and second-best premiums for different insurance market structures. The insurance program consists of an insurance premium, and marginal dependencies of that premium on speed and own safety technology choice of drivers. A private monopolist internalizes collision externalities up to the point where compensations to users' benefit matches the full (intangible) costs; in oligopolistic markets, insurers do not fully internalize collision externalities. Analytical results demonstrate how insurance firms' incentives to influence traffic safety coincide with or deviate from socially optimal incentives. Our results may be useful for design of pay-as-you-speed and alike insurances as well as policies related to driving safety.
\end{abstract}

Keywords: Road safety, collision externality, traffic regulation, congestion externality, second-best, car accident, car crash

JEL codes: D43, D62, R41, R42, R48

\section{Introduction}

Collision externalities are among the most important external costs of road transport: Parry et al. (2007) estimate that the social costs of road

\footnotetext{
${ }^{*}$ Corresponding author. Fax +31 20 5986004, phone +31 205986090 .

Email addresses: maria.b.dementyeva@gmail.com (Maria Dementyeva), e.t.verhoef@vu.nl (Erik T. Verhoef)
} 
crashes for the US correspond to around 4.3\% of the GDP, Elvik (2000) concludes that "rough estimates of road accident costs amounting both to 2 and $1 \%$ of GNP can be defended as reasonable, depending on whether or not an economic valuation of lost quality of life is included in the accident costs", and Peden et al. (2004) provides in Chapter 2 a survey on the total annual costs of road crashes to high-, middle- and low-income countries. Both drivers' behaviour (such as speeding, distance to the next car, attention paid towards the other road users) and technical characteristics (such as safety belts, advanced braking systems, windshields, lights, weight, etc.) of vehicles heavily influence the safety of the car driver and passengers, as well as of others on the road. This conclusion has been drawn from both empirical ${ }^{1}$ and theoretical works. ${ }^{2}$ Reanalysis (Aarts and van Schagen (2006)) of the data from Kloeden et al. (2001) revealed an exponential function between individual speed and the risk of being involved in a crash on urban roads. Also, on urban roads the accident rate increases more with increasing speed than on rural roads. Cohen and Einav (2003) state that seat belt usage enforcement greatly reduced traffic fatalities: "We estimate that a 1-percentage-point increase in usage saves 136 lives (using a linear specification), and a 1\% increase in usage reduces occupant fatalities by about $0.13 \%$ (using a log-log specification)".

Furthermore, Delhaye (2007), Rizzi (2008), and Hultkrantz et al. (2012), observe that incentives stemming from insurance can change drivers' behaviour. However, the effect of insurance companies efforts and incentives to affect driver behaviour remain under-investigated in the economic literature. For instance, based on Steimetz (2004), and Gossner and Picard (2005), Rizzi (2008) considers a rational driver who optimally chooses risk-reducing efforts (care), such as speed, distance between the cars etc., in a model where car insurance is available. Rizzi clearly shows that insurance influences drivers' efforts to drive safely. However, in his work insurance agents do not play an active role controlling drivers' choice, and only drivers' utility functions are maximized, that is, the insurance agents disregard the external costs the drivers impose.

The insurance model we consider is inspired by car tracking technologies,

\footnotetext{
${ }^{1}$ see, for example, Lave (1985), Cohen and Einav (2003), Aarts and van Schagen (2006), Steimetz (2008), Hultkrantz and Lindberg (2011), Hultkrantz et al. (2012)

${ }^{2}$ see, for instance, Jansson (1994), Verhoef and Rouwendal (2004), Nitzsche and Tscharaktschiew (2013), Wang (2013)
} 
such as GPS. The latest developments allow tracking tools to be cheap and efficient, and nowadays many vehicle producers include such equipment in the default versions of their cars. Bigger insurance companies offer Pay-As-YouDrive (PAYD) and its extension Pay-As-You-Speed (PAYS) insurances in a few countries by now, among them the United Kingdom, Spain, Israel, and the Netherlands. In Japan, car sharing companies charge the rates according to their customers' driving behavior. The trial in Bolderdijk et al. (2011) shows that "PAYD resulted in modest, but significant reduction in speeding of young drivers". Lahrmann et al. (2012) studies combination of PAYS insurance providing economic incentive to drive within speed limits, with warning from intelligent speed adaptation system if speeding. The authors conclude that the decrease in speeding was statistically significant, although the effect decreased over time and had no educating effect. Hultkrantz and Lindberg (2011a) reported an economic field-experiment that also resulted in significant reduction of speed-limit violations made by participants compared to non-participants. The study suggested that economic incentive schemes may be an effective tool to increase road safety. Hultkrantz et al. (2012) build an analytical model of self-selected PAYS extension of a mandatory insurance and illustrate their findings using Swedish data. It was established that PAYS insurance makes up for the gap between external cost of speeding and expected revenue of speeding tickets. Insurances based on the actual vehicle use and intelligent tracking systems, are more actuarially accurate. This neutralizes asymmetric information in insurance market and may decrease social costs of driving and make road use safer.

Dementyeva et al. (2015) study the efficiency of regulated and unregulated insurance markets, taking into account the interactions between the markets for road trips and the market for traffic safety insurance. In that model, we assumed that road users' behaviour involves just one margin: how much to drive. In this paper we extend the model, and insurance companies can now also influence road users' choices in terms of investments in private car safety for drivers, and speed. The latter may benefit the driver as well as a possible "partner" in a collision. A social regulator, in turn, has instruments to affect insurance providers, and thus indirectly also the drivers. We consider insurance to be mandatory.

Our model describes a two-stage game between obligatory car insurance providers and road users. First, insurance companies maximize their profit by optimizing aggregate kilometrage via insurance premium levels, and the choices of speed and technology via dependency of premiums on these choices, 
subject to equilibrium constraints. Then, each atomistic road user opts for a safety technology and speed, in order to minimize its generalized price per kilometer driven. (We assume drivers to be symmetric in terms of their travel cost functions.) Next, an aggregate kilometrage results from the inverse demand function for trips, given this optimized generalized price. This generalized price includes time costs, investments in own safety technology, insurance premiums, and a (possibly intangible) part of the expected collision costs in so far as it is not covered by insurance.

The crash cost per kilometer grows with aggregate kilometrage reflecting increasing chances of collisions, and thus the generalized price of driving depends on it. We furthermore assume that an individual's speed choice affects both one's own and other road users' safety, while the technology affects only the former. The technology chosen by a driver could in reality also influence the safety level of other road users, but distinguishing between a strictly internal safety measures (technology investment) and a combined internalexternal safety measure (speed) is helpful for a clear interpretation of our results. In our terminology, 'own safety technologies' include, for example, air bags, interior head-impact protection, seat belts, child car seats, flammability of interior materials, etc. Advanced braking systems, tire-pressure monitoring system, high intensity lamps would rather be included into the other characteristics of driving, affecting also the safety of others. We refer to such characteristics as 'speed'. Because a higher investment in technology reduces the safety benefits of slowing down, our model reflects the well-known regularity that drivers may behave more recklessly when being better protected. ${ }^{3}$

Following and extending the reasoning provided in Verhoef and Rouwendal (2004) and Dementyeva et al. (2015), we obtain marginal conditions for the first- and second-best premiums, and their marginal dependencies of technology and speed. ${ }^{4}$ In our model we thus acknowledge that companies influence drivers' behavior via insurance programs. We consider a

\footnotetext{
${ }^{3}$ Another important feature that could have been included into the model is the weight of vehicle: Heavier vehicles increase the damage suffered by other vehicles in the event of a collision between vehicles while being safer for its own driver. However, mathematical properties would stay similar, and no additional fundamental insights would be delivered.

${ }^{4} \mathrm{~A}$ social regulator can then impose taxes or subsidies on companies and/or road users, fines for speeding over a certain speed limit, and other regulations. For the sake of transparency, we do not explicitly consider speed limits or other speed policies.
} 
social welfare-maximizing planner; a private profit-maximizing monopoly; and oligopolistic markets of firms playing Nash in a Cournot fashion assuming that firms choose their premiums and quantities ${ }^{5}$ taking quantities (not premiums) of others fixed. Note that the crucial difference between Cournot and Bertrand behaviour is not the choice between using price or quantity as a instrument, but the assumption on which of these two is believed to be constant for other players. To the best of our knowledge, there has been no empirical study on the question of whether insurance markets are better characterized as Cournot or Bertrand oligopolies. Therefore, the more basic model in Dementyeva et al. (2015) considers both, noting that Cournot can be considered a polar case where the severity of competition is minimized, given the number of firms, and that Bertrand outcomes have extra specific additive terms comparing to Cournot outcomes. Our analysis can thus be extended to Bertrand competition without, however, delivering new insights and at a cost of a higher analytical complexity.

A number of conclusions stand out: For each type of market structure, the insurance premium (function) that drivers face is defined by an insurance premium level in the equilibrium point, and the marginal dependence of that premium function on speed and technology, given by what we will call optimal "gradients" of the premium function with respect to the individual driver's choice of speed, and choice of technology (the latter is also modeled as a continuous variable). Although such a sophisticated, continuous design of insurance premiums may appear unrealistic, we model it this way in order to identify whether and how the company would prefer to affect speed and technology choices of its insurees, in an analytical setting that does not introduce additional second-best distortions arising from imperfect instruments.

The insurance premiums we derive reflect that monopolists fully internalize the collision externalities imposed by their drivers upon one another, while competing firms provide only partial internalization. The same is true for the optimal "gradients" of the premium with respect to the speed and technology choices of the road users, but the interactions naturally lead to different types and degrees of failures, and therefore corrections. These conclusions thus extend Dementyeva et al. (2015), who considered total kilometrage as the only margin of behaviour. By assumption made in the current model, a

\footnotetext{
${ }^{5}$ In this model, quantities refer to vehicle kilometers driven.
} 
safer technology may only influence driver's own crash costs, and does not directly affect the chance to be guilty of a collision. A driver's choice to reduce speed, on the other hand, decreases the risk to cause a collision and therewith other drivers' risks, and this fact is reflected in the publicly optimal use of the gradient of the premium.

The policy implications of the results vary. Both public and private insurers' objectives depend on the safety level on the road; however, the distinction between their objective functions causes different insurance premiums and gradients with respect to speed and technology choices. In order to compensate for non-optimal pricing (and, correspondingly, to fill the gap between the first- and second-best aggregate kilometrage), a social regulator can introduce subsidies and/or taxes, imposed on either the firms or the drivers. Such regulation was considered in Dementyeva et al. (2015), for both parametric and manipulable taxes. Correcting the speed and safety technology choices with socially imperfect incentives from privately set premiums requires the social regulator to have the ability to directly affect these same margins.

The paper is organized as follows: We introduce the model in section 2 . Then we start the analysis by finding the first-best social optimum in section 3. We continue with the analysis of an oligopolistic market of insurance firms, competing in Nash-Cournot manner. Section 4 provides us with the profit-optimizing insurance premiums, as well as the optimal (from insurers' point of view) regulations of speed and technology choices. Firms that do not have perfect control over all choices of their clients are considered in section 5. Section 6 concludes.

\section{Model description}

There are three types of actors in this model: Road users consume kilometers driven, and choose the speed at which to drive and vehicle technology. Insurance companies provide auto insurance to (partially) cover collision costs of the drivers. In doing so, they choose the premium per kilometer, which they can make dependent on speed and technology chosen by the insuree. Since it is the marginal dependence of the premium on speed and technology that matters in equilibrium, we will refer to this dependence as the "gradients" of the premium, with respect to speed and technology. Finally, the regulator aims to maximize social welfare; for instance by setting taxes or subsidies for drivers or insurers. 
One of the main assumptions of the model is that road users are homogeneous in costs, and are individually indefinitely small. Due to the atomistic nature of the drivers, we may assume that individual kilometrage driven by each of them is infinitesimal compared to the aggregate kilometrage driven in the network, so that there are no self-imposed accidents, and that each unit of consumption corresponds to a different driver. ${ }^{6}$ The terms "driver" and "atomistic distance driven", thus, may and will be used interchangeably, unless it causes confusion. Because aggregate kilometrage remains price sensitive, our assumption does not preclude total mobility to vary between scenarios and hence to co-determine their welfare properties. In order to emphasize the atomistic nature of units of consumption, we will also speak of "particles" in the continuum of kilometers driven. This aspect is important in the context of our paper, as it defines which part of marginal costs are internal and which are external to a driver.

We denote with $\bar{K}_{m}$ the set of the drivers/kilometers driven insured by firm $m, m=1, \ldots, N$, where $N$ is the total number of firms on the market; $\bar{K}=\bigcup_{m} K_{m}$. The cardinal number $K_{m}=\left|\bar{K}_{m}\right|$ is the total distance driven by insurees of firm $m . K=\left|\bigcup_{m=1}^{N} \bar{K}_{m}\right|=\sum_{m=1}^{N} K_{m}$ is the aggregate kilometrage of all drivers in the network.

Individual road user $k$ faces the following costs of driving: expected collision cost $C_{A_{k}}$, travel time cost $C_{T_{k}}$, and cost of investment into own safety technology $C_{M_{k}}$, all per kilometer driven.

The per-kilometer collision cost for driver $k$ is an additive function $C_{A_{k}}(\cdot)=$ $\sum_{m=1}^{N} K_{m} c_{k}^{m}\left(S_{k}, \mu_{k} ; \bar{S}_{m}\right)$, where subscript $k$ refers to driver $k$ (and atomistic distance $d k$ driven by driver $k$ ). The term $K_{m} c_{k}^{m}(\cdot)$ gives the expected costs of collision between individual $k$ and drivers insured by firm $m$. The function $C_{A_{k}}(\cdot)$ represents the collision cost per kilometer driven, and, thus, functions $c_{k}^{m}(\cdot)$, for all $m=1, \ldots, N$, are collision costs "per kilometer, per other drivers' kilometer". Here, speed $S_{k}$ and technology $\mu_{k}$ (both scalar) are chosen by the driver $k$. The notation $\bar{S}_{m}$ stands for a scalar function of generalized speed of all drivers insured by firm $m$ taking the continuum

\footnotetext{
${ }^{6}$ The assumption of atomistic drivers allows us to disregard decisions on personal total kilometrage. It is consistent with the idea of individual drivers being too small to influence the equilibrium outcomes, and avoids tedious specifications needed to prevent that an individual creates, while driving a certain kilometer, a possibility of hitting herself when driving another kilometer.
} 
of all particles' speeds from the set $\bar{K}_{m}$ as argument. ${ }^{7}$ Because drivers are symmetric by assumption, in equilibrium, generalized speed $\bar{S}_{m}$ is equal to the equilibrium speed $S_{m}^{*}$ of every driver insured by the firm $m$. Collision costs rise with individual and generalized speed going up, and decrease with growing own level of technology.

The time cost $C_{T_{k}}$ is a decreasing function of individual speed $S_{k}$ of driver $k$. The safety investment $C_{M_{k}}$ has the own safety technology level $\mu_{k}$ as its argument, and it grows while technology increases. The economic lifetime of a car is assumed to be proportional to distance driven, therefore the total spending on car is considered to be variable costs, proportional to kilometrage.

Insurance firms cover an exogenous (legally determined) share $\alpha$ of the drivers' collision costs. The assumption $0<\alpha<1$ reflects that insurance companies may fully cover material/monetary costs of drivers, but leave other intangible costs, such as emotional costs of drivers and valuation of life, limb and suffering, at least partly unreimbursed.

A driver $k$ insured by firm $l$ (i.e. $k \in \bar{K}_{l}$ ) minimizes his generalized price of driving when choosing $S_{k}$ and $\mu_{k}$ :

$$
\min _{S_{k}, \mu_{k}} p_{k}\left(S_{k}, \mu_{k}, \cdot\right)=\pi_{l}(\cdot)+(1-\alpha) C_{A_{k}}(\cdot)+C_{T_{k}}\left(S_{k}\right)+C_{M_{k}}\left(\mu_{k}\right),
$$

where $\pi_{l}(\cdot)$ is the insurance premium charged by the firm. The premium function depends on many parameters and variables, including individual speed $S_{k}$, speed functions $\bar{S}_{m}$, for every insurance company $m$, and own technology $\mu_{k}$, which the firm can affect via the premium gradients. We first assume that firms can affect both individual speed and technology using the appropriate gradients of the premium $\left(\frac{\partial \pi_{l}}{\partial S_{k}}\right.$ and $\left.\frac{\partial \pi_{l}}{\partial \mu_{k}}\right)$, and then section 5 and Appendix B assume that insurers have imperfect control and cannot set each of the three instruments (premium gradients and levels). Note that the premium gradients $\frac{\partial \pi_{l}}{\partial S_{k}}$ and $\frac{\partial \pi_{l}}{\partial \mu_{k}}$ can be set independent of the equilibrium premium level, and both the premium level and its gradient are present in the individual's minimization problem (1).

We assume that, for a given crash, the probabilities of guilt of both parties depend on their speeds. This is reflected by introducing a function

\footnotetext{
${ }^{7}$ This implies that marginal change in driver $k$ 's generalized costs $C_{A_{k}}$ when individual speed $S_{n}$ of driver $n$ insured by firm $l$ changes is $\left.\frac{\partial C_{A_{k}}}{\partial S_{n}}\right|_{k \neq n}=K_{l} \frac{\partial c_{k}^{l}}{\partial S_{l}} \cdot \frac{\partial \bar{S}_{l}}{\partial S_{n}}$, for $n$ and $k$ being insured by the same firm $l$.
} 
$\gamma_{k}^{m}\left(S_{k}, \bar{S}_{m}\right)$, which assigns the probability of guilt of driver $k$ for a given collision between driver $k$ and any other driver insured by firm $m .^{8}$ (Driver $k$ does not have to be insured by firm $m$.) In order to present the insurance firm's objective function, we assume that the drivers' cost functions are continuous on $\bar{K}$, which is satisfied for identical drivers, as we assume is the case, but also if distributions of preferences over drivers or kilometers are continuous. Insurer's profit is the difference between the firm's revenue, i.e. insurance premiums collected from all drivers $k \in \bar{K}_{l}$, and its payments of two sorts. One type of payments is coverage of the collision costs of own customers when they are guilty of causing a crash; the other type of payments is coverage of the collision costs of non-guilty parties who suffer from crashes caused by drivers of that firm. Firm's $l$ profit function $\Pi_{l}$ is then as follows:

$$
\begin{aligned}
\Pi_{l}(\cdot)= & \int_{\bar{K}_{l}} \pi_{l}\left(S_{k}, \mu_{k}\right) d k \\
& -\alpha \int_{\bar{K}_{l}} \sum_{m=1}^{N} \gamma_{k}^{m}\left(S_{k}, \bar{S}_{m}\right) K_{m} c_{k}^{m}\left(S_{k}, \mu_{k}, \bar{S}_{m}\right) d k \\
& -\alpha \sum_{m=1}^{N} \int_{\bar{K}_{m}}\left(1-\gamma_{x}^{l}\left(S_{x}, \bar{S}_{l}\right)\right) K_{l} c_{x}^{l}\left(S_{x}, \mu_{x}, \bar{S}_{l}\right) d x
\end{aligned}
$$

Let us go through equation (2) in more detail. The first integral in (2) sums up insurance premiums collected from every driver $k \in \bar{K}_{l}$, and, thus, gives the firm's revenue. The other two terms reflect the firm's expenses. An insurance firm covers collision costs if its client is the guilty party. The term on the second line represents the compensation paid to firm l's customers $k$ when having caused a crash. For each atomistic distance $d k$ driven by driver $k$ of firm $l, \alpha \sum_{m=1}^{N} \gamma_{k}^{m}(\cdot) c_{k}^{m}(\cdot)$ is the expected payment from firm $l$ to driver $k$ if a collision occurs and that driver $k$ is guilty (otherwise it is covered by the insurer of the "collision partner"). The first integral represents the total expenses of this kind, and it thus integrates over the drivers $k$ insured by the firm.

The final term in (2) represents the aggregate payment of the firm to non-

\footnotetext{
${ }^{8}$ Hence, $\gamma_{m}^{k}(\cdot)=1-\gamma_{k}^{m}(\cdot)$ is the probability of individual $k$ not being guilty of a crash with a driver insured by firm $m$, so that other driver is guilty. We choose the risk to cause a crash to be independent of safety technology choice $\mu_{k}$ in order to emphasize that $\mu_{k}$ only influences own expected collision costs of driver $k$.
} 
guilty parties of crashes. The term under the integral sign is the expected payment to the second driver $x$, when not guilty, who is involved in each crash caused by a guilty insuree of firm $l$. The non-guilty driver might be a client of firm $l$, or from any other firm $m$ on the market. Hence, we integrate over the sets $\bar{K}_{m}$ to sum up the expected collision costs of the victims of customers of firm $l$. For $m=l$, the integral covers the same drivers as the integral in the second term; for $m \neq l$, other drivers are covered, and we emphasize this by integrating over $x$ in the last integral. The values of the integrals in (2) depend on the domain of integration, and, hence, differ for $\bar{K}_{m}$, for all $m=1, \ldots, N$, even though the functional form of the expected collision costs is the same due to symmetry of the drivers.

Let $\mathcal{B}\left(K_{1}, \ldots, K_{N}\right)$ be the social benefit function, giving the user benefits of trips. Firm $l$ maximizes the profit (2) with respect to its total kilometrage $K_{l}$, speed $S_{k}$ and technology $\mu_{k}$ choices of its customers $k \in \bar{K}_{l}$, subject to equilibrium conditions where driver's willingness to pay for road use $\mathcal{D}_{l}\left(K_{1}, \ldots, K_{N}\right) \equiv \frac{\partial \mathcal{B}(\cdot)}{\partial K_{l}}$, is equal to the generalized price of road use:

$$
\pi_{l}^{*}=\mathcal{D}_{l}(\cdot)-(1-\alpha) C_{A}\left(S_{l}^{*}, \mu_{l}^{*}, S_{l}^{*}\right)-C_{T}\left(S_{l}^{*}\right)-C_{M}\left(\mu_{l}^{*}\right) .
$$

Here we skip the subscript $k$ referring to individual drivers, since homogeneous drivers insured by same firm make equal equilibrium speed and technology choices, and face equal costs.

From driver's minimization problem (1) we have following conditions:

$$
\frac{\partial p_{k}}{\partial S_{k}}=0, \quad \frac{\partial p_{k}}{\partial \mu_{k}}=0, \quad \forall k \in \bar{K}_{l} .
$$

The f.o.c. $\frac{\partial \Pi_{l}}{\partial K_{l}}=0$, subject to the equilibrium condition (3), gives the profit-maximizing insurance premium level; equations $\frac{\partial \Pi_{l}}{\partial S_{k}}=0$, and $\frac{\partial \Pi_{l}}{\partial \mu_{k}}=0$, for all $k \in \bar{K}_{l}$, subject to the individual driver's conditions (4), define the optimal sensitivity (or gradient) of the premium with respect to the speed and technology choices for every road user insured by firm $l$. Together, the optimal equilibrium premium level and the optimal gradients $\frac{\partial \pi_{l}}{\partial S_{k}}$ and $\frac{\partial \pi_{l}}{\partial \mu_{k}}$, for all $k \in \bar{K}_{l}$, determine the optimal insurance premium program for firm $l$.

\section{Social optimum}

A natural reference and benchmark is the first-best social optimum. We find this by solving the maximization problem for what we call the "social 
regulator", who maximizes social surplus, taken as the measure for social welfare:

$$
\max \mathcal{W}(\cdot)=\mathcal{B}(K)-\int_{\bar{K}}\left(C_{A_{k}}(\cdot)+C_{T_{k}}\left(S_{k}\right)+C_{M_{k}}\left(\mu_{k}\right)\right) d k
$$

The equilibrium condition (3) also applies in the social optimum: ${ }^{9}$

$$
\pi^{f b}(\cdot)=\mathcal{D}\left(K^{f b}\right)-(1-\alpha) C_{A}\left(S^{f b}, \mu^{f b}, S^{f b}\right)-C_{T}\left(S^{f b}\right)-C_{M}\left(\mu^{f b}\right) .
$$

In addition, every driver $n \in \bar{K}$ chooses own safety technology $\mu_{n}$ and individual speed $S_{n}$ such that the conditions (4) hold:

$$
\begin{aligned}
\frac{\partial \pi}{\partial \mu_{n}} & =-(1-\alpha) \frac{\partial C_{A_{n}}\left(\mu_{n}, \cdot\right)}{\partial \mu_{n}}-\frac{\partial C_{M_{n}}\left(\mu_{n}\right)}{\partial \mu_{n}}, \\
\frac{\partial \pi}{\partial S_{n}} & =-(1-\alpha) \frac{\partial C_{A_{n}}\left(S_{n}, \cdot\right)}{\partial S_{n}}-\frac{\partial C_{T_{n}}\left(S_{n}\right)}{\partial S_{n}} .
\end{aligned}
$$

In case of a monopolistic market, the collision cost function can be rewritten as follows: $C_{A_{n}}(\cdot)=K c_{n}^{1}\left(S_{n}, \mu_{n}, \bar{S}\right)$. Then, given first-best choice of speed and technology $S^{f b}, \mu^{f b}$, the f.o.c. is

$$
\frac{\partial \mathcal{W}}{\partial K}=\mathcal{D}\left(K^{f b}\right)-\left(C_{A}(\cdot)+C_{T}\left(S^{f b}\right)+C_{M}\left(\mu^{f b}\right)\right)-\int_{\bar{K}} \frac{\partial C_{A_{k}}(\cdot)}{\partial K} d k=0, \quad \forall n .
$$

Using equilibrium constraint (6), we can rewrite this equation and get the first-best equilibrium premium level:

$$
\pi^{f b}=\alpha C_{A}\left(S^{f b}, \mu^{f b}, \cdot\right)+K^{f b} \frac{\partial C_{A}}{\partial K},
$$

which essentially implies full internalization of the collision externalities that the drivers impose on each other plus a correction for the moral hazard problem of not considering all collision cost when a part of it is insured and, thus, borne by the insurer. Note that insurance premium level guaranties the optimal aggregate kilometrage, but does not directly motivate drivers to optimally choose their speeds and technologies.

\footnotetext{
${ }^{9}$ We use superscript ${ }^{f b}$ to refer to the first-best, and ${ }^{s b}$ for second-best outcomes.
} 
Let us therefore consider the socially optimal regulation towards speed and technology choices. The technology-related social optimality condition for driver $n$ is:

$$
\begin{aligned}
\frac{\partial \mathcal{W}}{\partial \mu_{n}} & =-\frac{\partial}{\partial \mu_{n}} \int_{\bar{K}}\left(C_{A_{k}}(\mu, \cdot)+C_{T_{k}}(\cdot)+C_{M_{k}}\left(\mu_{k}\right)\right) d k \\
& =-\frac{\partial C_{A_{n}}\left(\mu_{n} \cdot\right)}{\partial \mu_{n}}-\frac{\partial C_{M_{n}}}{\partial \mu_{n}}=0,
\end{aligned}
$$

reflecting that $\mu_{n}$ only affects collision cost for driver $n$. Substitution of (7) into (10) gives:

$$
\frac{\partial \pi}{\partial \mu_{n}}=\alpha \frac{\partial C_{A_{n}}\left(\mu_{n}, \cdot\right)}{\partial \mu_{n}}
$$

The first-best gradient captures the driver's insured responsibility for collision costs he is involved in, regardless of whether he will be guilty of the collision.

The first-order condition w.r.t. the driver's speed choice is:

$$
\begin{aligned}
\frac{\partial \mathcal{W}}{\partial S_{n}} & =-\frac{\partial}{\partial S_{n}} \int_{\bar{K}}\left(K c_{k}^{1}\left(S_{k}, \cdot\right)+C_{T_{k}}\left(S_{k}\right)+C_{M_{k}}(\cdot)\right) d k \\
& =-K \frac{\partial c_{n}^{1}\left(S_{n}, \cdot\right)}{\partial S_{n}}-\frac{\partial C_{T_{n}}\left(S_{n}\right)}{\partial S_{n}}-\int_{\bar{K} \backslash\{n\}} K \frac{\partial c_{k}^{1}(\cdot, \bar{S})}{\partial S_{n}} d k=0 .
\end{aligned}
$$

Combining conditions (8) and (12), we have:

$$
\frac{\partial \pi}{\partial S_{n}}=\alpha K \frac{\partial c_{n}^{1}\left(S_{n}, \cdot\right)}{\partial S_{n}}+\int_{\bar{K} \backslash\{n\}} K \frac{\partial c_{k}^{1}(\cdot, \bar{S})}{\partial S_{n}} d k .
$$

It is intuitive that a social regulator internalizes the full collision externality: the first term in (13) reflects the part of expected collision costs covered by the insurance and, thus, would not be taken into account by the driver himself, and the second term accounts for the entire collision externality imposed by the driver on all other drivers.

The reason why this second term is not weighted by $\alpha$, to make it correspond to the firm's compensation to other drivers, is that all drivers are insured with the same firm, and the uninsured collision cost that driver $n$ imposes on other drivers is fully translated into a reduced willingness to pay premium. The firm therefore also fully faces that uninsured part of the externality: not because it should be compensated, but because it depresses the willingness to pay premiums. Adding up the fractions $\alpha$ (compensation to be paid by the firm) and $1-\alpha$ (reduced willingness to pay for other insurees, a term unity remains); hence, the second term. 


\section{Firms playing Nash-Cournot fashion and controlling drivers' choices of technology and speed}

\subsection{Profit-maximizing insurance premium}

We now turn to the case of oligopolistic supply of insurance.

In order to choose a profit-maximizing insurance premium (per kilometer driven), an insurance firm $l$ solves the f.o.c.:

$$
\begin{aligned}
\frac{\partial \Pi_{l}}{\partial K_{l}}= & \frac{\partial}{\partial K_{l}} \int_{\bar{K}_{l}}\left(\mathcal{D}_{l}(\cdot)-(1-\alpha) C_{A_{k}}(\cdot)-C_{T_{k}}(\cdot)-C_{M_{k}}(\cdot)\right) d k & \} 1 s t \\
& -\alpha \frac{\partial}{\partial K_{l}} \int_{\bar{K}_{l}} \sum_{m=1}^{N} \gamma_{k}^{m}(\cdot) K_{m} c_{k}^{m}(\cdot) d k & \} 2 n d \\
& -\alpha \sum_{m=1}^{N} \frac{\partial}{\partial K_{l}} \int_{\bar{K}_{m}}\left(1-\gamma_{x}^{l}(\cdot)\right) K_{l} c_{x}^{l}(\cdot) d x=0, & \} 3 r d
\end{aligned}
$$

subject to the equilibrium condition, i.e. for equilibrium choice $S_{l}^{o}$ of speed and $\mu_{l}^{o}$ of technology (equal for all drivers of the same firm):

$$
\pi_{l}^{o}=\mathcal{D}_{l}\left(K_{l}^{o}, \cdot\right)-(1-\alpha) C_{A}\left(S_{l}^{o}, \mu_{l}^{o}, \cdot\right)-C_{T}\left(S_{l}^{o}\right)-C_{M}\left(\mu_{l}^{o}\right)
$$

We number the lines in (14) in order to make it easier to follow the

derivations and to interpret the terms in the final expression. Let us first do the derivations:

$$
\begin{array}{rlr}
\frac{\partial \Pi_{l}}{\partial K_{l}}= & (\underbrace{\mathcal{D}_{l}-(1-\alpha) C_{A}-C_{T}-C_{M}}_{\pi_{l}^{o}}) & \} 1 s t \\
& +\int_{\bar{K}_{l}}\left(\frac{\partial \mathcal{D}_{l}}{\partial K_{l}}-(1-\alpha) \frac{\partial C_{A_{k}}}{\partial K_{l}}\right) d k & \} 1 s t \\
& -\alpha \sum_{m=1}^{N} \gamma_{n}^{m} K_{m} c_{n}^{m}-\alpha \int_{\bar{K}_{l}} \gamma_{k}^{l} c_{k}^{l} d k & \\
& -\alpha \sum_{m=1}^{N} \int_{\bar{K}_{m}}\left(1-\gamma_{x}^{l}\right) c_{x}^{l} d x-\alpha\left(1-\gamma_{n}^{l}\right) K_{l} c_{n}^{l}=0, & \} 3 r d
\end{array}
$$


therefore, given the equilibrium $\left(S_{l}^{o}, \mu_{l}^{o}\right)$, the optimal premium level is:

$$
\begin{array}{rlrl}
\pi_{l}^{o}= & -K_{l}^{o} \frac{\partial \mathcal{D}_{l}}{\partial K_{l}}+(1-\alpha) K_{l}^{o} \frac{\partial C_{A_{n}}}{\partial K_{l}} & \} 1 s t \\
& +\alpha \sum_{m=1}^{N} \gamma_{n}^{m}(\cdot) K_{m}^{o} c_{n}^{m}(\cdot)+\alpha K_{l}^{o} \gamma_{n}^{l}(\cdot) c_{n}^{l}(\cdot) & \} 2 n d \\
& +\alpha \sum_{m=1}^{N} K_{m}^{o}\left(1-\gamma_{m}^{l}\right) c_{m}^{l}(\cdot)+\alpha\left(1-\gamma_{n}^{l}\right) K_{l}^{o} c_{n}^{l}(\cdot) . & & \} 3 r d
\end{array}
$$

In (16), the insurance premium (per kilometer driven) is followed by the demand related mark-up, plus a term that captures the marginal customer's depressing effect on firm l's other customers' aggregate willingness to pay. The latter mimics the motivation of private road operators to internalize congestion externalities (Edelson (1971); Mills (1981)). The terms in the second line refer to additional payments from firm $l$ to its own customers when these are guilty. The first of these is the (expected) payment to the additional driver when guilty. The second term represents the increase in payments to firm l's inframarginal drivers, which have an increased probability of being guilty in a crash due to the marginal increase in $K_{l}$. The terms on the third line refer to additional payments from firm $l$ to non-guilty drivers, possibly insured by $l$ and possibly by other firms. The first term covers payments when insured driver is guilty; it sums over all other drivers on the road, including those insured by firm $l$. The second term represents the additional payments on the firms' inframarginal insurances, when these drivers cause a crash and the marginal driver is the non-guilty partner and must still be compensated by firm $l$, because the guilty driver is also insured by firm $l$.

Let us note that for private profit-maximizing monopoly case, $N=1$, the insurance premium (17) reduces to:

$$
\pi^{m o n}=-K^{m o n} \frac{\partial \mathcal{D}}{\partial K}+\alpha C_{A}\left(S^{m o n}, \mu^{m o n}, \cdot\right)+K^{m o n} \frac{\partial C_{A}}{\partial K} .
$$

The private monopolist makes drivers compensate fully for their expected collision costs, as well as for their impact on the other drivers on the road due to negative externality. Quite intuitively, and as will be elaborated below, on top of the market mark-up, a term is added which is equal to the socially optimal price rule (9). 


\subsection{Optimal speed and technology choice}

Also for oligopolists, insurance programs include rules or gradients to control drivers' choices of speed and own safety technology.

Let us first analyze how insurance providers can influence individual drivers' choice of safety technology level. Each driver insured with firm $l$ $\left(n \in \bar{K}_{l}\right)$ looks for a technology $\mu_{n}$ to balance the investments and the safety, therefore, minimizing the own generalized price (1):

$$
\frac{\partial p_{n}}{\partial \mu_{n}}=\frac{\partial \pi_{l}(\cdot)}{\partial \mu_{n}}+(1-\alpha) \frac{\partial C_{A_{n}}\left(\cdot, \mu_{n}\right)}{\partial \mu_{n}}+\frac{\partial C_{M_{n}}\left(\mu_{n}\right)}{\partial \mu_{n}}=0,
$$

which is equivalent to

$$
\frac{\partial \pi_{l}(\cdot)}{\partial \mu_{n}}=-(1-\alpha) K_{l} \frac{\partial c_{n}^{l}\left(\mu_{n}, \cdot\right)}{\partial \mu_{n}}-\frac{\partial C_{M_{n}}\left(\mu_{n}\right)}{\partial \mu_{n}}, \quad \forall n \in \bar{K}_{l} .
$$

From firm l's perspective, individual's choice must optimize firm's expected profit (2):

$$
\begin{array}{rlr}
\frac{\partial \Pi_{l}}{\partial \mu_{n}}= & \frac{\partial}{\partial \mu_{n}} \int_{\bar{K}_{l}}(\underbrace{\mathcal{D}_{l}(\cdot)-(1-\alpha) \sum_{m=1}^{N} K_{m} c_{k}^{m}\left(\mu_{k}, \cdot\right)-C_{T_{k}}(\cdot)-C_{M_{k}}\left(\mu_{k}\right)}_{\pi_{l}}) d k & \} 1 s t \\
& \left.-\alpha \frac{\partial}{\partial \mu_{n}} \int_{\bar{K}_{l} \sum_{m=1}^{N} \gamma_{k}^{m}(\cdot) K_{m} c_{k}^{m}\left(\mu_{k}, \cdot\right) d k}\right\} 2 n d \\
& -\alpha \sum_{m=1}^{N} \frac{\partial}{\partial \mu_{n}} \int_{\bar{K}_{m}}\left(1-\gamma_{x}^{l}(\cdot)\right) K_{l} c_{x}^{l}\left(\mu_{x}, \cdot\right) d x=0, \quad \forall n \in \bar{K}_{l} . & \} 3 r d
\end{array}
$$

In order to make the derivations more transparent, let us point out that among all integrals in (20), only those taken over the domain $\bar{K}_{l}$ have terms depending on choice $\mu_{n}$ made by an individual $n \in \bar{K}_{l}$, and that each driver's choice appears among $\mu_{k}$ in the second line and among $\mu_{x}$ in the third. Let 
us do the derivations, and take into account the driver's trade-off (19):

$$
\begin{aligned}
\frac{\partial \Pi_{l}}{\partial \mu_{n}}= & -(1-\alpha) \sum_{m=1}^{N} K_{m} \frac{\partial c_{n}^{m}\left(\mu_{n}, \cdot\right)}{\partial \mu_{n}}-\frac{\partial C_{M_{n}}\left(\mu_{n}\right)}{\partial \mu_{n}} \\
& -\alpha \underbrace{\sum_{m=1}^{N} \gamma_{n}^{m}(\cdot) K_{m} \frac{\partial c_{n}^{m}}{\partial \mu_{n}}}_{2 n d}-\underbrace{\alpha\left(1-\gamma_{n}^{l}\right) K_{l} \frac{\partial c_{n}^{l}}{\partial \mu_{n}}}_{3 r d} \\
= & \frac{\partial \pi_{l}}{\partial \mu_{n}}-\alpha \sum_{m=1}^{N} \gamma_{n}^{m} K_{m} \frac{\partial c_{n}^{m}\left(\mu_{n}, \cdot\right)}{\partial \mu_{n}}-\alpha\left(1-\gamma_{n}^{l}\right) K_{l} \frac{\partial c_{n}^{l}\left(\mu_{n}, \cdot\right)}{\partial \mu_{n}}=0 .
\end{aligned}
$$

Hence, insurance firm's control for the premium gradient w.r.t. personal technology is as follows:

$$
\frac{\partial \pi_{l}}{\partial \mu_{n}}=\alpha \sum_{m=1}^{N} \gamma_{n}^{m}(\cdot) K_{m} \frac{\partial c_{n}^{m}}{\partial \mu_{n}}+\alpha\left(1-\gamma_{n}^{l}\right) K_{l} \frac{\partial c_{n}^{l}}{\partial \mu_{n}} .
$$

To interpret this gradient condition, let us go back to equation (20). The terms relating to the 1 st line of (20) represent the impact of $\mu_{n}$ on driver $n$ 's private cost. Because this translates directly into willingness to pay premium, the firm takes this effect fully into account. The term stemming from the 2nd line can be seen as a moral hazard term: it is that part of damage incurred by driver $n$ himself when guilty that he would ignore in setting $\mu_{n}$ because it is insured. Hence, it is $\alpha$ times the marginal impact of $\mu_{n}$ upon self-inflicted collision costs. The 3rd line reflects the marginal savings for firm $l$ on compensation to particle $n$ when other drivers insured by firm $l$ cause a crash with particle $n$. There is no further firm-internal externalities involved for this particular firm, as the safety technology choice only influences own safety and by assumption does not affect any other driver directly. Of course, for cross-firm effects there are externalities, but those are not taken into account by firm $l$.

Comparing condition (21) with formula (11) for the gradient of a regulator maximizing social surplus, we can see that the oligopolistic gradient with respect to technology lacks the part of a driver's marginal collision costs covered by the firm-insurer $m \neq l$ of the driver guilty of a crash (in case when driver $n$ is the injured party). However, a private monopolist's optimal gradient coincides with the first-best one, and fully internalized driver's responsibility. 
Let us now turn to individual speed choice analysis. From driver's $n \in \bar{K}_{l}$ perspective, in marginal terms the costs of driving have to be compensated by benefits from speeding up:

$$
\frac{\partial p_{n}}{\partial S_{n}}=\frac{\partial \pi_{l}}{\partial S_{n}}+(1-\alpha) \frac{\partial C_{A_{n}}\left(S_{n}, \cdot\right)}{\partial S_{n}}+\frac{\partial C_{T_{n}}\left(S_{n}\right)}{\partial S_{n}}=0, \quad \forall n \in \bar{K}_{l} .
$$

Equivalently,

$$
\frac{\partial \pi_{l}}{\partial S_{n}}=-(1-\alpha) \frac{\partial C_{A_{n}}\left(S_{n}, \cdot\right)}{\partial S_{n}}-\frac{\partial C_{T_{n}}\left(S_{n}\right)}{\partial S_{n}}, \quad \forall n \in \bar{K}_{l} .
$$

An insurer maximizes its profit for each driver $n$ it insures by taking the partial derivative with respect to $S_{n}$ :

$$
\begin{aligned}
\frac{\partial \Pi_{l}}{\partial S_{n}}= & \frac{\partial}{\partial S_{n}} \int_{\bar{K}_{l}}\left(\mathcal{D}_{l}(\cdot)-(1-\alpha) C_{A_{k}}\left(S_{k}, \bar{S}, \cdot\right)-C_{T_{k}}\left(S_{k}\right)-C_{M_{k}}(\cdot)\right) d k & \} 1 s t \\
& -\alpha \frac{\partial}{\partial S_{n}} \int_{\bar{K}_{l}} \sum_{m=1}^{N} \gamma_{k}^{m}\left(S_{k}, \bar{S}_{m}\right) K_{m} c_{k}^{m}\left(S_{k}, \bar{S}_{m}, \cdot\right) d k & \} 2 n d \\
& -\alpha \sum_{m=1}^{N} \frac{\partial}{\partial S_{n}} \int_{\bar{K}_{m}}\left(1-\gamma_{x}^{l}\left(S_{x}, \bar{S}_{l}\right)\right) K_{l} c_{x}^{l}\left(S_{x}, \mu_{x}, \bar{S}_{l}\right) d x=0 . & \} 3 r d
\end{aligned}
$$


Equivalently ${ }^{10}$ :

$$
\begin{aligned}
& \frac{\partial \pi_{l}}{\partial S_{n}}=\underbrace{\int_{\bar{K}_{l} \backslash\{n\}}(1-\alpha) K_{l} \cdot \frac{\partial c_{k}^{l}}{\partial \bar{S}_{l}} \frac{\partial \bar{S}_{l}}{\partial S_{n}} d k}_{1.1} \\
& +\underbrace{\alpha \sum_{m=1}^{N} \frac{\partial \gamma_{n}^{m}}{\partial S_{n}} K_{m} c_{n}^{m}}_{2.1}+\underbrace{\alpha \sum_{m=1}^{N} \gamma_{n}^{m} K_{m} \frac{\partial c_{n}^{m}}{\partial S_{n}}}_{2.2} \\
& +\underbrace{\alpha \int_{\bar{K}_{l} \backslash\{n\}} \frac{\partial \gamma_{k}^{l}}{\partial \bar{S}_{l}} \frac{\partial \bar{S}_{l}}{\partial S_{n}} K_{l} c_{k}^{l} d k}_{2.3}+\underbrace{\alpha \int_{\bar{K}_{l} \backslash\{n\}} \gamma_{k}^{l} K_{l} \frac{\partial c_{k}^{l}}{\partial \bar{S}_{l}} \frac{\partial \bar{S}_{l}}{\partial S_{n}} d k}_{2.4} \\
& -\underbrace{\alpha \sum_{m=1}^{N} \int_{\bar{K}_{m} \backslash\{n\}} \frac{\partial \gamma_{x}^{l}}{\partial \bar{S}_{l}} \frac{\partial \bar{S}_{l}}{\partial S_{n}} K_{l} c_{x}^{l} d x}_{3.1} \\
& +\underbrace{\alpha \sum_{m=1}^{N} \int_{\bar{K}_{m} \backslash\{n\}}\left(1-\gamma_{x}^{l}\right) K_{l} \frac{\partial c_{x}^{l}}{\partial \bar{S}_{l}} \frac{\partial \bar{S}_{l}}{\partial S_{n}} d x}_{3.2} \\
& -\underbrace{\alpha \frac{\partial \gamma_{n}^{l}}{\partial S_{n}} K_{l} c_{n}^{l}}_{3.3}+\underbrace{\alpha\left(1-\gamma_{n}^{l}\right) K_{l} \frac{\partial c_{n}^{l}}{\partial S_{n}}}_{3.4}
\end{aligned}
$$

Here we have three channels of $n$ 's speed choice influence: $S_{n}$ directly affects the probability of inflicting self-damage via the cost incurred given being guilty, and via the probability of being guilty, and indirectly via the generalized speed $\bar{S}_{l}$ as an argument of collision cost functions as well as the probabilities of being involved in a crash when not being guilty.

The term 1.1 reflects changes of other drivers of firm $l$ willingness to pay for insurance, as speeding of $n$ increases collision costs of other drivers through the generalized speed $\bar{S}_{l}$. Comparing the other terms with those obtained for technology choice in eq. (21), we spot some similarities. As such, the term 2.2 mirrors the first term from (21), and being now accompanied by terms 2.1, 2.3, and 2.4, it represents the moral hazard, namely, self-induced

\footnotetext{
${ }^{10}$ One can find detailed derivations in Appendix A
} 
collision cost covered by insurance and, thus, not taken into account by the driver. The last term 3.4 of (24) mirrors the last term in (21), and now together with $3.1,{ }^{11} 3.2$, and 3.3 , it is equal to a compensation to driver $n$ when another driver of firm $l$ is guilty. Because, in contrast to what we assumed for the technology, speed not only affects one's own expected collision costs but also those of fellow drivers, we get additional terms in (24) compared to (21). In particular, terms 2.1 and 3.3 reflect that individual speed $S_{n}$ affects the probability $\gamma_{n}^{m}$ to cause a crash and to be involved in one as a non-guilty party. When the guilty party is insured by firm $l$, the cost are firm-internal, and hence firm $l$ finds it optimal to adjust the gradient accordingly. Terms 2.3, 2.4, 3.1, and 3.2 reflect indirect effect of individual speed choice on collision costs and probabilities of guilt via generalized speed $\bar{S}_{l}$.

The monopolistic gradient follows as a special case from (24) and is represented as follows:

$$
\frac{\partial \pi_{1}}{\partial S_{n}}=\alpha K \frac{\partial c_{n}^{1}}{\partial S_{n}}+\int_{\bar{K} \backslash\{n\}} K \frac{\partial c_{k}^{1}}{\partial \bar{S}_{1}} \frac{\partial \bar{S}_{1}}{\partial S_{n}} d k .
$$

The difference between the first-best gradient (13) and monopolist's one (25) only stems from the difference between the first best and oligopolistic aggregate kilometrage. This conclusion is in line with intuition as both the social planner and a monopolist consider collision costs of all drivers regardless of the drivers' role in collisions (characterized by parameters $\gamma_{k}^{1}$ ), and thus fully internalize the external impact of driver's $n$ behaviour.

\section{Insurance market with imperfect control of speed or technology choice}

Let us now consider the case where firms do not have perfect control over all three margins. We assume now that firms charge drivers insurance premiums that do not depend on speed choices. Firms therefore cannot influence drivers' speed directly, but can take into account drivers' incentives to balance marginal collision costs and time spent on the road, which is given by:

$$
(1-\alpha) \frac{\partial C_{A_{n}}}{\partial S_{n}}+\frac{\partial C_{T_{n}}}{\partial S_{n}}=0, \quad \forall n \in \bar{K}_{l}
$$

\footnotetext{
${ }^{11}$ In this term, $\bar{K}_{m} \backslash\{n\}=\bar{K}_{m}$, for all $m \neq l$, as $n \in \bar{K}_{l}$.
} 
This is equivalent to

$$
(1-\alpha) \sum_{m=1}^{N} K_{m} \frac{\partial c_{n}^{m}}{\partial S_{n}}+\frac{\partial C_{T_{n}}}{\partial S_{n}}=0, \quad \forall n \in \bar{K}_{l} .
$$

Furthermore, the equilibrium condition for aggregate kilometrage becomes:

$$
\tilde{\pi}_{l}=\mathcal{D}_{l}(\cdot)-(1-\alpha) C_{A_{k}}(\cdot)-C_{T_{k}}\left(S_{k}\right)-C_{M_{k}}\left(\mu_{k}\right) .
$$

Firm $l$ maximizes its profit (2), where the premium $\pi_{l}$ is now substituted by a new premium $\tilde{\pi}_{l}$, which is not regulated by speed restrictions:

$$
\begin{aligned}
\tilde{\Pi}_{l}(\cdot)= & \int_{\bar{K}_{l}} \tilde{\pi}_{l}(\cdot) d k \\
& -\alpha \int_{\bar{K}_{l}} \sum_{m=1}^{N} \gamma_{k}^{m}\left(S_{k}, \bar{S}_{m}\right) K_{m} c_{k}^{m}\left(S_{k}, \mu_{k}, \bar{S}_{m}\right) d k \\
& -\alpha \sum_{m=1}^{N} \int_{\bar{K}_{m}}\left(1-\gamma_{x}^{l}\left(S_{x}, \bar{S}_{l}\right)\right) K_{l} c_{x}^{l}\left(S_{x}, \mu_{x}, \bar{S}_{l}\right) d x
\end{aligned}
$$

with respect to the equilibrium conditions (26) and (27). The Lagrangian of this maximization problem is

$$
L_{l}=\tilde{\Pi}_{l}+\lambda_{S}\left((1-\alpha) \sum_{m=1}^{N} K_{m} \frac{\partial c_{n}^{m}}{\partial S_{n}}+\frac{\partial C_{T_{n}}}{\partial S_{n}}\right),
$$

where the Lagrangian multiplier $\lambda_{S}$ is the shadow price reflecting the marginal impact of condition (26) on optimized profits. The higher the shadow price, the stronger the inability of insurance company to control drivers' speed influences its profit, and so is the adjustment for the remaining instruments to imperfectly compensate for this. Analysis of this Lagrangian will provide us with a new, second-best insurance premium, as well as a second-best gradient with respect to the driver's own safety technology. We discuss this and the analytical representation of $\lambda_{S}$ below, but first present the second-best optimum premium and gradient for technology under this constraint, leaving $\lambda_{S}$ as a variable in our analytical expressions. 
The f.o.c. for the Lagrangian with respect to aggregate kilometrage $K_{l}$ is:

$$
\begin{aligned}
\frac{\partial L_{l}}{\partial K_{l}} & =\frac{\partial \tilde{\Pi}_{l}}{\partial K_{l}}+\lambda_{S} \frac{\partial}{\partial K_{l}}\left((1-\alpha) \sum_{m=1}^{N} K_{m} \frac{\partial c_{n}^{m}}{\partial S_{n}}+\frac{\partial C_{T_{n}}}{\partial S_{n}}\right) \\
& =\frac{\partial \tilde{\Pi}_{l}}{\partial K_{l}}+\lambda_{S}(1-\alpha) \frac{\partial c_{n}^{l}}{\partial S_{n}}=0
\end{aligned}
$$

Because $\frac{\partial \tilde{\Pi}_{l}}{\partial K_{l}}$ in (30) takes on the same form as $\frac{\partial \Pi_{l}}{\partial K_{l}}$ in the original firm problem (14), the new premium per kilometer driven is:

$$
\tilde{\pi}_{l}=\pi_{l}-\lambda_{S}(1-\alpha) \frac{\partial c_{n}^{l}}{\partial S_{n}}
$$

where $\pi_{l}$ represents the analytical expression in (17). The last term in (31) corrects for the inability to directly affect speed choice, and only takes care of the uninsured part of collision costs within the firm. The fact that the per kilometer collision costs are different (typically, higher) when speed cannot be affected will be reflected already in the different equilibrium values for the variables in $\pi_{l}$.

The f.o.c. with respect to individual safety technology choice $\mu_{n}$ is:

$$
\begin{aligned}
\frac{\partial L_{l}}{\partial \mu_{n}} & =\frac{\partial \tilde{\Pi}_{l}}{\partial \mu_{n}}+\lambda_{S} \frac{\partial}{\partial \mu_{n}}\left((1-\alpha) \sum_{m=1}^{N} K_{m} \frac{\partial c_{n}^{m}}{\partial S_{n}}+\frac{\partial C_{T_{n}}}{\partial S_{n}}\right) \\
& =\frac{\partial \tilde{\Pi}_{l}}{\partial \mu_{n}}+\lambda_{S}(1-\alpha) K_{l} \frac{\partial^{2} c_{n}^{l}}{\partial S_{n} \partial \mu_{n}}=0 .
\end{aligned}
$$

Comparing (32) to (20), the last term of (32) shows that the stronger interrelation between driver's speed and technology choices is, the higher the indirect control of the firm is, and the more strongly it will adjust the gradient with respect to $\mu_{n}$ in order to also affect $S_{n}$. Since drivers only react to the change of uninsured part of the costs, assuming the rest covered by the insurer, this cross-effect is multiplied by $(1-\alpha)$. In this extra term, the insurance firm internalizes only internal collision costs, and ignores those crashes where other firms' clients are involved. The latter implies that a larger firm has more powerful instruments to influence its drivers' behavior as it fines drivers for a larger share of the collision externality they impose on others. 
Finally, the f.o.c. with respect to individual speed $S_{n}$ allows us to find an analytical representation of the Lagrangian multiplier $\lambda$ :

$$
\begin{aligned}
\frac{\partial L_{l}}{\partial S_{n}} & =\frac{\partial \tilde{\Pi}_{l}}{\partial S_{n}}+\lambda_{S} \frac{\partial}{\partial S_{n}}\left((1-\alpha) \frac{\partial C_{A_{n}}}{\partial S_{n}}+\frac{\partial C_{T_{n}}}{\partial S_{n}}\right) \\
& =\frac{\partial \tilde{\Pi}_{l}}{\partial S_{n}}+\lambda_{S}\left((1-\alpha) \frac{\partial^{2} C_{A_{n}}}{\partial S_{n}^{2}}+\frac{\partial^{2} C_{T_{n}}}{\partial S_{n}^{2}}\right)=0 .
\end{aligned}
$$

From (33) we obtain the Lagrangian multiplier $\lambda$, equal to the marginal firm's profit over the marginal relaxation of the condition (26):

$$
\lambda_{S}=-\frac{\partial \tilde{\Pi}_{l} / \partial S_{n}}{(1-\alpha) \frac{\partial^{2} C_{A_{n}}}{\partial S_{n}^{2}}+\frac{\partial^{2} C_{T_{n}}}{\partial S_{n}^{2}}} .
$$

The magnitude of the shadow price $\lambda_{S}$ (and so an incentive of insurance firm to control its drivers' speed choice via premiums and optimal "gradients" for technology) is proportional to firm's marginal profit with respect to individual speed choice, in the numerator of (34). The higher the losses a firm faces due to speeding, the stronger will be its effort to use available instruments to control the speed choice. On the other hand, $\lambda_{S}$ is inversely proportional to the marginal change of the equilibrium condition (26), which reflects the sensitivity of the equilibrium perceived price with respect to speed. The closer the denominator to zero, the higher is the speed change induced in reaction to the firm's manipulation of speed via the instruments available to the firm ( $\mu_{n}$ and $K_{l}$, here), because drivers will have to make a larger adjustment in speed to achieve equilibrium again. The role of the denominator is thus to reduce $\lambda$ when perceived price reacts strongly to $S_{n}$, as this implies that a change in that price will induce only a relatively small adjustment in $S_{n}$.

Lack of firm's control over drivers' choice of own safety technology in the presence of (firm's) speed regulation, as well as an inability to control either of the variables $S_{n}$ and $\mu_{n}$, are not conceptually different from the case we have just considered, and will therefore not be presented analytically. The corresponding Lagrangian multipliers of the cross effects are the following:

$$
\lambda_{M}=-\frac{\partial \bar{\Pi}_{l} / \partial \mu_{n}}{(1-\alpha) \frac{\partial^{2} C_{A_{n}}}{\partial \mu_{n}^{2}}+\frac{\partial^{2} C_{M_{n}}}{\partial \mu_{n}^{2}}},
$$

where $\bar{\Pi}_{l}$ stands for the profit of firm whilst insurance premium is considered to be dependent on speed but not on technology. 
Appendix B presents the case where the firm can only set a premium, independent of individual's speed or technology choice. The firm hence has to compensate for lack of control over optimal gradients control by adapting its insurance premium level.

\section{Conclusion}

In this paper we analyzed car insurance schedules that allow insurance firms and a social regulator to influence safety on the road via multiple controls over individual drivers' behavior. We compare the first-best social optimum with an insurance market of private profit-maximizing firms, given that insurance is obligatory. The insurance premium schedules that we consider consist of the equilibrium insurance premium level, along with what we call the "gradients" of the premium function with respect to the individual driver's choices of speed and own safety technology. Speed may be considered to represent all the individual choices of drivers that influence both the drivers' own and other drivers' safety. Unlike speed, safety technology by our assumption only decreases drivers' own collision costs, without influencing other drivers' safety directly. But it does affect other drivers' behaviour indirectly, through risk compensation mechanisms via speed adjustments. Congestion was not considered, meaning that individual speed does not directly depend on the number of drivers entering the road, but indirectly there is a channel via speed adjustment in the face of higher traffic volumes.

The expressions we derive for the three policy instruments in the different scenarios are complex and hard to decompose, and thus hard to compare between scenarios. In Appendix C, we try to give a systematic account. In this concluding section we discuss the main conclusions just verbally. ${ }^{12}$

Our main framework assumes that insurance firms can control both speed and technology choices of the drivers. In that case, companies offer insurance at a certain premium per kilometer driven, and use the optimal gradients in order to motivate drivers to choose a certain equilibrium speed and technology. The insurance premium is thus characterized by three choices by the insurance company: the level of the premium and the two gradients. The

\footnotetext{
${ }^{12}$ Tables C.2-C.5 explain the notations used in summarizing Table C.1, and provide the intuition behind every term. Table C.1 includes formulas of optimal premium levels and gradients with respect to driving characteristics, "rephrased" in the way that makes comparison of the results more transparent.
} 
level is used to affect kilometrage. Similar to what was found in Dementyeva et al. (2015), the profit maximizing premium internalizes part of the externality but not all of it, as long as there are more than one insurer on the market. The implied tax regulation of insurance premium levels developed there stays relevant in this extended model.

The internalization of externalities by an insurance firm is also reflected in the marginal dependence of the premium functions on individual's speed and technology level (see formulae (11), (13), (21), and (24)). When setting the optimal profit-maximizing gradients, the firm again only partly internalizes marginal externalities imposed by its insurees upon other drivers. That is, it takes care only of that part of the total collision costs it has to cover, and ignores the costs covered by other firms, as well as other firms' drivers' own risks. For instance, in case of technology control, this implies that an insurance firm's optimal gradient is less steep than the one of a social regulator; that is, a social regulator is stricter to an individual driver's choice of own safety technology, than a private firm, and a larger firm is stricter, than a firm with lower market power. A private profit-maximizing monopolist's gradients coincide with the first-best ones, if aggregate kilometrage were the same. We also note that a monopolist faces the full externality, and not only the insured part of it which has to be compensated. The uninsured part depresses the willingness to pay premiums by its own customers, and is thus included into the optimal premium level and the optimal gradient with respect to individual speed choice.

We also considered the case of imperfect control over drivers' behavior. When only one of the two "gradient" variables (e.g., technology choice) can be controlled by the insurance firm directly, the other one (here, speed) can still be controlled indirectly via the insurance premium, and by the gradient of the first one. The corresponding optimization problem represents a second-best problem. The associated solutions for the insurance premium and the remaining optimal gradient include, in the Lagrangian multiplier, terms correcting for the lack of control over the third margin. The stronger the mutual dependence between driver's speed and technology is, the more effective indirect control of insurance firm is. Also, a firm with larger market power implies a higher degree of internalization of collision externalities. Thus, a larger firm has better instruments of indirect control. The higher the losses a firm faces due to speeding, the stronger will be its effort to use accessible instruments to control the speed choice. The role of the corrective term is reduced when the perceived price reacts strongly to individual 
speed, as this means that a change in that price will induce a relatively small adjustment in speed.

The results achieved in this paper can be used for evaluation of road safety policies. Adjustment of the insurance premium level was thoroughly studied in Dementyeva et al. (2015). Depending on the number of insurance firms in the market and their size, a social regulator can introduce subsidies or taxes in order to correct for the collision externalities uninternalized by insurance firms. A no-claim policy can be used as an instrument to implement the optimal gradients by the firms. According to our analysis, such means as (upper) speed and (lowest) technology limits, as well as other possible regulative actions, are needed even when (oligopolistic) firms manage to influence drivers' behaviour directly. Only a private profit-maximizing monopolist would give the same incentive for drivers to choose their own safety technology as a social regulator would, and only so if aggregate kilometrage were the same.

Insurance schemes that implement premium gradients can be operationalized in multiple ways, including the use of penalties for risky driving. Likewise, drivers choosing PAYS insurance might get certain bonuses (against traditional insurance) for careful behavior. Such tools receive increasing attention and were discussed, among others, in Bolderdijk et al. (2011), Hultkrantz and Lindberg (2011a), and Lahrmann et al. (2012).

This paper also offers some perspective on future research. Our model includes a number of important assumptions. The first to mention is that the model is deterministic. While in reality many processes and variables of the road traffic are better described as stochastic, for the moment, we exclude any of it from our consideration. Furthermore, we excluded possible congestion (and so its influence on speed choice), the drivers were assumed to be symmetric, information about expected collision costs as well as about the dependence of insurance premiums on speed and technology was full and available equally to all actors on the market,and the parameter $\alpha$ is assumed to be exogenous. Relaxation of these assumptions such as including drivers' diversity (they can have different value of time or safety, level of income, location, be more or less dangerous and/or risk-averse), and considering asymmetric information and stochastic elements (notably, crashes), gives possible directions to further develop the model. Heterogeneity of drivers would call for product differentiation, for instance, for making insured share of crash costs endogenous or even considering insurance deductibles; i.e. fixed amount that drivers have to pay in the event of a crash rather than proportional shares 
of the costs.

These extensions will further complicate the analysis and may, indeed, be viable only in numerical exercises, but there is no reason to expect they could overturn or invalidate the conclusions that we have drawn with respect to the social efficiency of the choice of premiums and gradients that imperfectly competitive firms make in the context of car insurance policies.

\section{Acknowledgements}

Financial support from the ERC, Advanced Grant OPTION (\#246969), is gratefully acknowledged. Furthermore, we would like to thank Robin Lindsey, Paul Koster, and the three anonymous reviewers for their thoughtful comments and suggestions. Any remaining errors remain our responsibility. 


\section{Appendix A.}

Let us do the derivations of optimal premium gradient with respect to individual speed (23):

$$
\left.\begin{array}{rlrl}
\frac{\partial \Pi_{l}}{\partial S_{n}}= & -(1-\alpha) \frac{\partial C_{A_{n}}\left(S_{n}, \cdot\right)}{\partial S_{n}}-\frac{\partial C_{T_{n}}\left(S_{n}\right)}{\partial S_{n}}-\int_{\bar{K}_{l} \backslash\{n\}}(1-\alpha) \frac{\partial C_{A_{k}}\left(S_{k}, \bar{S}_{l}, \cdot\right)}{\partial S_{n}} d k & \} 1 s t \\
& -\alpha \sum_{m=1}^{N}\left(\frac{\partial \gamma_{n}^{m}}{\partial S_{n}} K_{m} c_{n}^{m}+\gamma_{n}^{m} K_{m} \frac{\partial c_{n}^{m}}{\partial S_{n}}\right) & \\
& -\alpha \int_{\bar{K}_{l} \backslash\{n\}}\left(\frac{\partial \gamma_{k}^{l}}{\partial S_{n}} K_{l} c_{k}^{l}+\gamma_{k}^{l} K_{l} \frac{\partial c_{k}^{l}}{\partial S_{n}}\right) d k & \\
& -\alpha \sum_{m=1}^{N} \int_{K_{m} \backslash\{n\}}\left(-\frac{\partial \gamma_{x}^{l}}{\partial S_{n}} K_{l} c_{x}^{l}+\left(1-\gamma_{x}^{l}\right) K_{l} \frac{\partial c_{x}^{l}}{\partial S_{n}}\right) d x & \\
& -\alpha\left(-\frac{\partial \gamma_{n}^{l}}{\partial S_{n}} K_{l} c_{n}^{l}+\left(1-\gamma_{n}^{l}\right) K_{l} \frac{\partial c_{n}^{l}}{\partial S_{n}}\right) & \\
= & \frac{\partial \pi_{l}}{\partial S_{n}}-\int_{\bar{K}_{l} \backslash\{n\}}(1-\alpha) K_{l} \cdot \frac{\partial c_{k}^{l}\left(S_{k}, \mu_{k}, \bar{S}_{l}\right)}{\partial S_{n}} d k & \\
& -\alpha \sum_{m=1}^{N}\left(\frac{\partial \gamma_{n}^{m}}{\partial S_{n}} K_{m} c_{n}^{m}+\gamma_{n}^{m} K_{m} \frac{\partial c_{n}^{m}}{\partial S_{n}}\right) &
\end{array}\right\} 2 n d
$$




\section{Appendix B. Insurance market with no control over speed or tech- nology choices}

Once a private profit-maximizing firm does not have control of speed or technology choice of its drivers, it solves the following constrained maximization problem: $\max \hat{\Pi}_{l}$ with premiums that do not directly reflect individual speed and safety technology. The equilibrium constraints are:

$$
\begin{array}{r}
\hat{\pi}_{l}(\cdot)=D_{l}-(1-\alpha) C_{A_{n}}-C_{T_{n}}-C_{S_{n}}, \\
(1-\alpha) \frac{\partial C_{A_{n}}}{\partial \mu_{n}}+\frac{\partial C_{M_{n}}}{\partial \mu_{n}}=0, \\
(1-\alpha) \frac{\partial C_{A_{n}}}{\partial S_{n}}+\frac{\partial C_{T_{n}}}{\partial S_{n}}=0 .
\end{array}
$$

We will use notations cond $M$ and cond $S$ for the expressions on the lefthand side (B.2) and (B.3). We work with the corresponding Lagrangian that includes $\hat{\lambda}_{M}$ and $\hat{\lambda}_{S}$, the Lagrangian multipliers of cond $M$ and cond $S$, respectively:

$$
\hat{L}=\hat{\Pi}_{l}+\hat{\lambda}_{M} \cdot \operatorname{cond} M+\hat{\lambda}_{S} \cdot \operatorname{cond} S .
$$

From FOCs we conclude that the Lagrangian multipliers are a solution of the following linear system:

$$
\begin{aligned}
& \frac{\partial \hat{\Pi}_{l}}{\partial S_{n}}+\hat{\lambda}_{M} \cdot \frac{\partial \operatorname{cond} M}{\partial S_{n}}+\hat{\lambda}_{S} \cdot \frac{\partial \operatorname{cond} S}{\partial S_{n}}=0 \\
& \frac{\partial \hat{\Pi}_{l}}{\partial \mu_{n}}+\hat{\lambda}_{M} \cdot \frac{\partial \operatorname{cond} M}{\partial \mu_{n}}+\hat{\lambda}_{S} \cdot \frac{\partial \operatorname{cond} S}{\partial \mu_{n}}=0
\end{aligned}
$$

Solving the system, we get:

$$
\begin{gathered}
\hat{\lambda}_{M}=-\left|\begin{array}{cc}
\frac{\partial \hat{\Pi}_{l}}{\partial S_{n}} & \frac{\partial \operatorname{condS}}{\partial S_{n}} \\
\frac{\partial \Pi_{l}}{\partial \mu_{n}} & \text { cross }
\end{array}\right| /\left|\begin{array}{cc}
\text { cross } & \frac{\partial \operatorname{cond} S}{\partial S_{n}} \\
\frac{\partial \operatorname{cond} M}{\partial \mu_{n}} & \text { cross }
\end{array}\right|, \\
\hat{\lambda}_{S}=-\left|\begin{array}{cc}
\text { cross } & \frac{\partial \hat{\Pi}_{l}}{\partial S_{n}} \\
\frac{\partial \operatorname{condM} M}{\partial \mu_{n}} & \frac{\partial \hat{\Pi}_{l}}{\partial \mu_{n}}
\end{array}\right| /\left|\begin{array}{cc}
\text { cross } & \frac{\partial \operatorname{cond} S}{\partial S_{n}} \\
\frac{\partial \operatorname{cond} d M}{\partial \mu_{n}} & \operatorname{cross}
\end{array}\right|,
\end{gathered}
$$

where cross stands for the cross-effects $\frac{\partial c o n d M}{\partial S_{n}}$ and $\frac{\partial c o n d S}{\partial \mu_{n}}$, both being equal to $\frac{\partial^{2} C_{n}}{\partial S_{n} \partial \mu_{n}}$.

The resulting Lagrangian multipliers $\hat{\lambda}_{M}$ and $\hat{\lambda}_{S}$ are not (easily) representable via the analytical forms of $\lambda_{S}$ from (34) and $\lambda_{M}$ from (35), and do not allow clear intuitive interpretation. We therefore leave it out of the main paper. 
Appendix C. Summarizing and comparing policy rules across scenarios 
Table C.1: Summarizing table

\begin{tabular}{|c|c|c|c|}
\hline & Social planner & $\begin{array}{l}\text { Private profit-maximizing } \\
\text { monopoly }\end{array}$ & Oligopoly \\
\hline premium & $(9): \alpha A+B$ & (18): $\alpha A+B+M$ & $\begin{array}{l}(17): M_{l}+(1-\alpha) B_{l}+\alpha \gamma A_{l}+\alpha \gamma B_{l} \\
+\alpha(1-\gamma) A_{-l}+\alpha(1-\gamma) B_{l} \\
=M_{l}+B_{l}+\alpha \gamma A_{l}+\alpha(1-\gamma) A_{-l}\end{array}$ \\
\hline $\begin{array}{l}\text { gradient wrt indi- } \\
\text { vidual technology } \\
\text { choice }\end{array}$ & $(11): \alpha \frac{\partial A}{\partial \mu}$ & $\alpha \frac{\partial A}{\partial \mu}$ & $(21): \alpha \gamma \frac{\partial A_{l}}{\partial \mu}+\alpha(1-\gamma) \frac{\partial a_{l}}{\partial \mu}$ \\
\hline $\begin{array}{l}\text { gradient wrt indi- } \\
\text { vidual speed choice }\end{array}$ & (13): $\alpha \frac{\partial A}{\partial S}+H$ & $(25): \alpha \frac{\partial A}{\partial S}+H$ & $\begin{array}{l}\text { (24): }(1-\alpha) h_{l} \\
+\alpha \frac{\partial \gamma}{\partial S} A_{l}+\alpha \gamma \frac{\partial A_{l}}{\partial S}+\alpha \frac{\partial \gamma}{\partial S} g_{l}+\alpha \gamma h_{l} \\
-\alpha \frac{\partial \gamma}{\partial S} G_{l}+\alpha(1-\gamma) H_{l}-\alpha \frac{\partial \gamma}{\partial S} a_{l}+\alpha(1-\gamma) \frac{\partial a_{l}}{\partial S}\end{array}$ \\
\hline
\end{tabular}


Table C.2: Notations for summarizing Table C.1

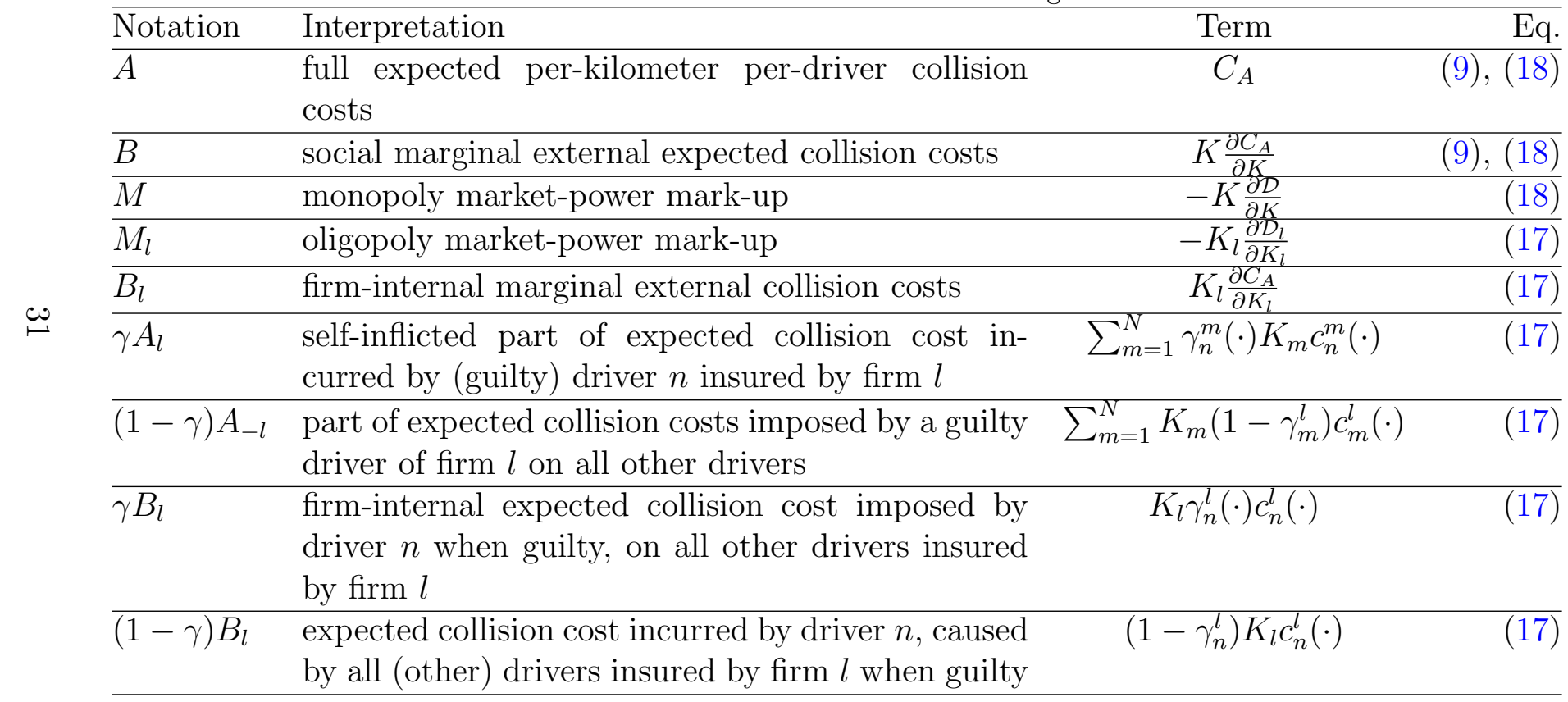


Table C.3: Notations for summarizing Table C.1

\begin{tabular}{llcc}
\hline Notation & Interpretation & Term & Eq. \\
\hline$H$ & $\begin{array}{l}\text { social marginal external expected collision cost } \\
\text { with respect to driver } n \text { 's speed }\end{array}$ & $\int_{\bar{K} \backslash\{n\}} K \frac{\partial c_{k}^{1}}{\partial \bar{S}} \frac{\partial \bar{S}}{\partial S_{n}} d k$ & $(13),(25)$ \\
\hline$\frac{\partial A}{\partial S}$ & $\begin{array}{l}\text { marginal private expected collision cost with re- } \\
\text { spect to own speed for driver } n\end{array}$ & $\frac{\partial C_{A_{n}}\left(S_{n}, \cdot\right)}{\partial S_{n}}$ & $(13),(25)$ \\
\hline$\frac{\partial A}{\partial \mu}$ & $\begin{array}{l}\text { marginal private expected collision costs with re- } \\
\text { spect to own technology choice for driver } n\end{array}$ & $\frac{\partial C_{A_{n}}\left(\mu_{n}, \cdot\right)}{\partial \mu_{n}}$ & $(11)$ \\
\hline$\gamma \frac{\partial A_{l}}{\partial \mu}$ & $\begin{array}{l}\text { self-inflicted part of marginal expected collision } \\
\text { cost with respect to own technology choice in- }\end{array}$ & $\sum_{m=1}^{N} \gamma_{n}^{m}(\cdot) K_{m} \frac{\partial c_{n}^{m}}{\partial \mu_{n}}$ & $(21)$ \\
& curred by (guilty) driver $n$ insured by firm $l$ & & \\
\hline$(1-\gamma) \frac{\partial a_{l}}{\partial \mu}$ & $\begin{array}{l}\text { expected marginal collision cost incurred by driver } \\
\text { n caused by all other drivers insured by firm } l\end{array}$ & $\left(1-\gamma_{n}^{l}\right) K_{l} \frac{\partial c_{n}^{l}}{\partial \mu_{n}}$ & \\
\hline$h_{l}$ & $\begin{array}{l}\text { firm-internal marginal external expected collision } \\
\text { cost imposed by driver } n \text { due to his speed choice }\end{array}$ & $\int_{\bar{K}_{l} \backslash\{n\}} K_{l} \frac{\partial c_{k}^{l}}{\partial S_{l}} \frac{\partial \bar{S}_{l}}{\partial S_{n}} d k$ & $(24), 1.1$ \\
& on all other drivers insured by firm $l$ & & \\
\hline
\end{tabular}


Table C.4: Notations for summarizing Table C.1

\begin{tabular}{|c|c|c|c|}
\hline Notation & Interpretation & Term & Eq. \\
\hline$\frac{\partial \gamma}{\partial S} A_{l}$ & $\begin{array}{l}\text { self-inflicted part of marginal expected collision cost incurred } \\
\text { by (guilty) driver } n \text { with respect to speed choice, via the chan- } \\
\text { nel of guilt probability only }\end{array}$ & $\sum_{m=1}^{N} \frac{\partial \gamma_{n}^{m}}{\partial S_{n}} K_{m} c_{n}^{m}$ & $(24), 2.1$ \\
\hline$\frac{\partial \gamma}{\partial S} a_{l}$ & $\begin{array}{l}\text { firm-internal part of marginal external expected collision cost } \\
\text { with respect to speed imposed by driver } n \text { 's choice of speed } \\
\text { via the channel of guilt probability only }\end{array}$ & $\frac{\partial \gamma_{n}^{l}}{\partial S_{n}} K_{l} c_{n}^{l}$ & $(24), 3.3$ \\
\hline$\frac{\partial \gamma}{\partial S} G_{l}$ & $\begin{array}{l}\text { ignored by firm } l \text { marginal external expected collision cost } \\
\text { imposed by driver } n \text { 's speed choice on other drivers via the } \\
\text { channel of guilt probability only }\end{array}$ & $\sum_{m=1}^{N} \int_{\bar{K}_{m} \backslash\{n\}} \frac{\partial \gamma_{x}^{l}}{\partial \bar{S}_{l}} \frac{\partial \bar{S}_{l}}{\partial S_{n}} K_{l} c_{x}^{l} d x$ & $(24), 3.1$ \\
\hline$\frac{\partial \gamma}{\partial S} g_{l}$ & $\begin{array}{l}\text { firm-internal marginal external expected collision } \\
\text { cost imposed by driver } n \text { 's speed choice on other drivers } \\
\text { insured by firm } l \text { via the channel of guilt probability only }\end{array}$ & $\int_{\bar{K}_{l} \backslash\{n\}} \frac{\partial \gamma_{k}^{l}}{\partial \bar{S}_{l}} \frac{\partial \bar{S}_{l}}{\partial S_{n}} K_{l} c_{k}^{l} d k$ & $(24), 2.3$ \\
\hline$\overline{\gamma \frac{\partial A_{l}}{\partial S}}$ & $\begin{array}{l}\text { self-inflicted part of marginal expected } \\
\text { collision cost incurred by driver } n \text { 's choice of speed } \\
\text { when guilty via the channel of (expected per-kilometer } \\
\text { per-driver) collision cost only }\end{array}$ & $\sum_{m=1}^{N} \gamma_{n}^{m} K_{m} \frac{\partial c_{n}^{m}}{\partial S_{n}}$ & $(24), 2.2$ \\
\hline
\end{tabular}


Table C.5: Notations for summarizing Table C.1

\begin{tabular}{|c|c|c|c|}
\hline Notation & Interpretation & Term & Eq. \\
\hline$(1-\gamma) \frac{\partial a_{l}}{\partial S}$ & $\begin{array}{l}\text { firm-internal part of marginal external expected } \\
\text { collision cost self-imposed by driver n's choice of } \\
\text { speed when not being guilty via the channel of } \\
\text { (expected per-kilometer per-driver) collision cost } \\
\text { only }\end{array}$ & $\left(1-\gamma_{n}^{l}\right) K_{l} \frac{\partial c_{n}^{l}}{\partial S_{n}}$ & $(24), 3.4$ \\
\hline$\gamma h_{l}$ & $\begin{array}{l}\text { firm-internal marginal external expected collision } \\
\text { cost imposed by driver } n \text { 's choice of speed on all } \\
\text { other drivers insured by firm } l \text { when these drivers } \\
\text { are guilty via the channel of generalized group } \\
\text { speed only }\end{array}$ & $\int_{\bar{K}_{l} \backslash\{n\}} \gamma_{k}^{l} K_{l} \frac{\partial c_{k}^{l}}{\partial \bar{S}_{l}} \frac{\partial \bar{S}_{l}}{\partial S_{n}} d k$ & $(24), 2.4$ \\
\hline$(1-\gamma) H_{l}$ & $\begin{array}{l}\text { marginal external expected collision cost imposed } \\
\text { on other non-guilty road users due to driver } n \text { 's } \\
\text { speed choice via the channel of generalized group } \\
\text { speed only when drivers insured by firm } l \text { are guilty }\end{array}$ & $\sum_{m=1}^{N} \int_{\bar{K}_{m} \backslash\{n\}}\left(1-\gamma_{x}^{l}\right) K_{l} \frac{\partial c_{x}^{l}}{\partial S_{l}} \frac{\partial \bar{S}_{l}}{\partial S_{n}} d x$ & $(24), 3.2$ \\
\hline
\end{tabular}




\section{References}

Letty Aarts and Ingrid van Schagen. Driving speed and the risk of road crashes: A review. Accident Analysis and Prevention, 38(2):215 - 224, 2006. URL http://www.sciencedirect.com/science/article/ pii/S0001457505001247.

J.W. Bolderdijk, J. Knockaert, E.M. Steg, and E.T. Verhoef. Effects of payas-you-drive vehicle insurance on young drivers' speed choice: Results of a dutch field experiment. Accident Analysis and Prevention, 43(3):1181 1186, 2011. ISSN 0001-4575. doi: http://dx.doi.org/10.1016/j.aap.2010. 12.032. URL http://www.sciencedirect.com/science/article/pii/ S0001457510004094.

Alma Cohen and Liran Einav. The effects of mandatory seat belt laws on driving behavior and traffic fatalities. Review of Economics and Statistics, 85(4):828 - 843, 2003. URL http://dx.doi.org/10.1162/ 003465303772815754 .

Eef Delhaye. Economic analysis of traffic safety. Phd thesis, Katholieke Universiteit Leuven, July 2007.

Maria Dementyeva, Paul R. Koster, and Erik T. Verhoef. Regulation of road accident externalities when insurance companies have market power. Journal of Urban Economics, 86(0):1 - 8, 2015. URL http://www . sciencedirect.com/science/article/pii/S0094119014000941.

Noel M. Edelson. Congestion tolls under monopoly. The American Economic Review, 61(5):873-882, 1971. ISSN 00028282. URL http://www.jstor. org/stable/1813147.

Rune Elvik. How much do road accidents cost the national economy? Accident Analysis \& Prevention, 32(6):849 - 851, 2000. ISSN 0001-4575. doi: http://dx.doi.org/10.1016/S0001-4575(00)00015-4. URL http:// wWw.sciencedirect.com/science/article/pii/S0001457500000154.

Olivier Gossner and Pierre Picard. On the consequences of behavioral adaptations in the cost-benefit analysis of road safety measures. Journal of Risk and Insurance, 72(4):577-599, 2005. URL http://dx.doi.org/10.1111/ j.1539-6975.2005.00139.x. 
Lars Hultkrantz and Gunnar Lindberg. Accident cost, speed and vehicle mass externalities, and insurance. Technical Report 2011-26, Transport economics Stockholm, 2011.

Lars Hultkrantz and Gunnar Lindberg. Pay-as-you-speed: An economic field experiment. Journal of Transport Economics and Policy, 45(3):415-436, 2011a. URL http://www. jstor.org/stable/23072198.

Lars Hultkrantz, Jan-Eric Nilsson, and Sara Arvidsson. Voluntary internalization of speeding externalities with vehicle insurance. Transportation Research Part A: Policy and Practice, 46(6):926 - 937, 2012. URL http: // www. sciencedirect.com/science/article/pii/S0965856412000298.

Jan Owen Jansson. Accident externality charges. Journal of Transport Economics and Policy, 28, 1994.

C.N. Kloeden, G. Ponte, and A.J. McLean. Travelling speed and the rate of crash involvement on rural roads. Technical Report CR 204, Australian Transport Safety Bureau ATSB, Civic Square, ACT, 2001.

Harry Lahrmann, Niels Agerholm, Nerius Tradisauskas, Kasper K. Berthelsen, and Lisbeth Harms. Pay as you speed, ISA with incentives for not speeding: Results and interpretation of speed data. Accident Analysis and Prevention, 48:17 - 28, 2012. ISSN 0001-4575. doi: http://dx.doi. org/10.1016/j.aap.2011.03.015. URL http://www.sciencedirect.com/ science/article/pii/S0001457511000650. Intelligent Speed Adaptation + Construction Projects.

Charles A. Lave. Speeding, coordination, and the $55 \mathrm{mph}$ limit. The American Economic Review, 75(5):1159-1164, 1985. URL http://www. jstor. org/stable/1818655.

David E. Mills. Ownership arrangements and congestion-prone facilities. The American Economic Review, 71(3):493-502, 1981. ISSN 00028282. URL http://www . jstor .org/stable/1802798.

Eric Nitzsche and Stefan Tscharaktschiew. Efficiency of speed limits in cities: A spatial computable general equilibrium assessment. Transportation Research Part A: Policy and Practice, 56(0):23 - 48, 2013. URL http:// www. sciencedirect.com/science/article/pii/S096585641300150X. 
Ian W. H. Parry, Margaret Walls, and Winston Harrington. Automobile externalities and policies. Journal of Economic Literature, 45(2):373399, 2007. URL http://www. jstor. org/stable/27646797.

Margie Peden, Richard Scurfield, David Sleet, Dinesh Mohan, Adnan A. Hyder, Eva Jarawan, and Colin Mathers. World report on road traffic injury prevention. Technical report, World Health Organization, 2004. URL http://whqlibdoc. who.int/publications/2004/9241562609.pdf.

Luis Ignacio Rizzi. Integrating travel delays, road safety, care, vehicle insurance and cost-benefit analysis of road capacity expansion in a unified framework. Networks and Spatial Economics, 8(2-3):125-140, 2008. URL http://dx.doi.org/10.1007/s11067-007-9047-2.

Seiji S.C. Steimetz. New Methods for Modeling and Estimating the Social Costs of Motor Vehicle Use. Phd thesis, UC Berkeley: University of California Transportation Center, 2004.

Seiji S.C. Steimetz. Defensive driving and the external costs of accidents and travel delays. Transportation Research Part B: Methodological, 42(9):703 - 724, 2008. URL http://www.sciencedirect.com/science/article/ $\mathrm{pii} / \mathrm{S} 0191261508000167$.

Erik T. Verhoef and Jan Rouwendal. A behavioural model of traffic congestion: Endogenizing speed choice, traffic safety and time losses. Journal of Urban Economics, 56(3):408 - 434, 2004. URL http://www. sciencedirect.com/science/article/pii/S0094119004000592.

Shuaian Wang. Efficiency and equity of speed limits in transportation networks. Transportation Research Part C: Emerging Technologies, 32(0):61 - 75, 2013. URL http://www.sciencedirect.com/science/article/ pii/S0968090X13000764. 